Sir Douglas Ritchie, chairman of the Executive Committee of the Dock and Harbour Authorities Association, pointed out how difficult it has proved to detect offenders under the Oil in Navigable Waters Act, particularly as some part of the pollution of inland tidal waters is caused by oil discharged, or escaping, many miles away at sea and being carried to the coasts. He described the facilities which have been provided for the collection of oily water in ports and stated that these have, unfortunately, not been used to any real extent. His Association welcomes the recommendations of the Faulkner Committee and has made it clear that it would be prepared to co-operate in providing, or securing the provision of, adequate reception facilities at the ports.

In May 1952 an independent Scandinavian Committee on Oil Pollution of the Sea, consisting of representatives from Finland, Sweden, Norway and Donmark, was set up at an international meeting of sportsmen in Finland. This committee was represented at the London Conference by its chairman, Captain Berno von Bornstedt, and Major Bertil Funck (Sweden), with Mr. Mogens Blach, director of the Port of Copenhagen, and Mr. MoltkeLeth, of the Danish Hunting Society. Mr. Blach described the havoc caused by oil pollution on Danish shores and mentioned the voluntary efforts in abstaining from the discharge of waste oil made by Danish shipowners. He said that it is understood in Denmark that the evil cannot be eliminated until international agreement is reached, and it is felt that it is the duty of any interested country to do everything possible to have the question dealt with on an international basis. Major Bertil Funck outlined the measures regarding oil pollution which have been taken in Sweden and referred to the recommendations which were made at the Baltic and International Maritime Conference in Stockholm in 1951. He stated that the Scandinavian Committee supports the recommendations of the British report and proposes that the Scandinavian Governments should. as soon as possible, seek the agreement of the Baitic and North Sea countries for fixing a date after which discharge of persistent oils into the sea should be prohibited.

A report from Mr. Banks Belt, chairman of the Atlantic Waterfowl Council, New York, directed special attention to the need for educating crews in care in preventing oil pollution.

Dr. H. Lillie, formerly a surgeon with an antarctic whaling fleet, urged that whatever legislation is introduced internationally should cover operations of the whaling industry in the Antarctic and other seas. He described half-grown seals covered in a thick tarry mess, their eyes bloodshot with irritation, and penguins hopelessly clogged waiting a slow death.

Sir John Simonsen, speaking on the need for further research, stated that the separation of oil-water emulsions is not a problem easy of solution. What is required is a plant cheap to buy, occupying little space and requiring for its operation the minimum of technical control. Plants and methods are in use which have proved successful, but further work is necessary. If governments insist, and it is hoped they will, that oil pollution must cease, research on this problem might well be undertaken in a govern ment research institute. It would require the joint work of a physical chemist and chemical engineer. Two speakers described plants for dealing with waste oil, and Mr. W. Killner stated that the process he has developed while in Admiralty service does not require specialized technique or elaborate equipment and is suitable for use in merchant ships. Full information is in the hands of the National Research Development Corporation.

At the close of the Conference a declaration of aims was unanimously adopted, supporting the view that ships of all nations should be required to refrain from discharging persistent oils into the sea, noting with satisfaction the co-operation of the shipping industry and oil companies, recognizing the need for international agreement and undertaking to stimulate public opinion regarding this, welcoming the announcement of the Minister of Transport regarding the calling of an international conference and urging that statutory provision be made to ensure adequate facilities for the reception of oily residues at ports, oil-loading terminals and repair yards.

In addition to the representatives of Belgium, Denmark, Finland, Sweden, Norway, the Netherlands and South Africa who attended the Conference, twenty-six nations were represented by observers from their embassies, legations, diplomatic missions and high commissioners in London.

\section{STANDARDIZATION OF RADIOACTIVE ISOTOPES IN GREAT BRITAIN}

\author{
BY W. E. PERRY \\ National Physical Laboratory, Teddington
}

CINCE the end of 1950 , four organizations in $\$$ Great Britain-Atomic Energy Research Establishment, National Physical Laboratory, Radiotherapeutic Research Unit of the Medical Research Council and Royal Cancer Hospital-have been collaborating in the measurement of radioactive isotopes on an absolute basis, that is, in determining the number of disintegrations per second in a given sample. It seems an appropriate moment to review very briefly the work which has been done so far; a fuller report on the measurements (up to the spring of 1953) is obtainable on application to the Director, National Physical Laboratory, Teddington.

The impetus for undertaking this work came partly from the recommendations of the Joint Commission on Radioactivity and of the International Commission on Radiological Units. The aim has been to assess the reliability of different methods, to improve and develop them, and to introduce ultimately a system of standardization appropriate to the more important isotopes, particularly those of relatively short half-life. Some users of radioactive isotopes are, of course, not much concerned with absolute values; but others, for example, clinical users, must have an absolute basis for their work with these substances.

At the outset a short list of the more important isotopes was drawn up, and it was hoped that an accuracy of the order of 2 per cent would be both adequate and attainable in their standardization. By the end of 1952 , samples of ten isotopes had been measured by counting and by ionization-chamber methods. The former included defined solid-angle $\beta$-particle counting with end-window Geiger-Müller 
counters, $4 \pi$-solid angle $\beta$-particle counting with Geiger-Müller and liquid scintillation counters, and $\beta \gamma$-coincidence counting. The samples were solutions prepared and distributed by the Atomic Energy Research Establishment, their activities ranging from about $0 \cdot 1$ to $8 \mathrm{mC}$. per gm. of solution.

The work has shown that the defined solid-angle method is not satisfactory for absolute measurements, owing to the complex absorption and scattering conditions ; it may, however, have a use as calibrated equipment. $4 \pi$-counter measurements have, on the whole, been satisfactory; thus sodium-24, phosphorus-32, bromine-82, strontium-90 and gold-198 have given values agreeing within about \pm 2 per cent; differences of about \pm 3 per cent have been found with potassium-42, cobalt-60, strontium-89 and iodine-131. Some inconsistencies may have been due to the chemical and other changes occurring during the dilution of solutions to the low level of activity required for the preparation of the sources.

The $\beta \gamma$-coincidence values for sodium-24 and cobalt- 60 determined by two laboratories have generally agreed to within \pm 1 per cent; but for isotopes with more complex modes of disintegration, the differences have been several per cent. There has been a tendency for the $\beta \gamma$-values to be greater than $4 \pi$-counter values; for cobalt-60, this may perhaps be due to the absorption of $\beta$-particles in the solid material in the source itself. It is hoped that improvements in technique will determine and remove these differences.

The $\gamma$-ray ionization measurements have been consistent to within \pm 1 per cent for sodium-24 and cobalt-60 and \pm 2 per cent for other isotopes. This method is indirect and involves a number of physical quantities, uncertainties in the numerical values of which preclude strict comparison with the direct. counting methods. However, taking these limitations into account, no serious discrepancies have occurred between the two types of measurement.

Following the measurements of the iodine-131 samples, it was decided to revise the British standard for this isotope ${ }^{1}$, and responsibility for its maintenance and the issue of standard samples was undertaken by the National Physical Laboratory. No formal specification of other standards has yet been made. The National Physical Laboratory has, however, begun the periodic issue ${ }^{2}$ of phosphorus-32 samples calibrated by the $4 \pi$-counter method.

During 1953 the scheme of measurements has been continued with the same group of isotopes, and samples have been interchanged with the U.S. National Bureau of Standards and the Atomic Energy of Canada, Ltd. A report on these measurements will be made in the near future.

1 Bullarl, E. C., Nature, 170, 916 (1952).

${ }^{2}$ Nature, 171, 676 (1953).

\section{NEWS and VIEWS}

\section{Zoology and Applied Entomology at the Imperial} College, London:

Prof. J. W. Munro, C.B.E.

THE retirement of Prof. J. W. Munro from the chair of zoology and applied entomology at Imperial College of Science and Technology, London, brings to an end a long association with the College. After a period as assistant professor of entomology, he succeeded Prof. F. Balfour Browne as professor of entomology in 1929, and in 1934, on the retirement of Prof. E. W. MacBride from the chair of zoology, he assumed responsibility, as professor of zoology and applied entomology, for teaching and research in zoology as well as in entomology. The appointment of Prof. Munro marked not so much a new phase in the development of the Department as a re-affirmation of the purpose of the College "to give the highest specialized instruction, and to provide the fullest equipment for the most advanced training and research in various branches of science, especially in its application to industry". It is against this background that Prof. Munro's achievements are to be recognized. With foresight and method he brought his experience as a forest entomologist to a different field, that of the study and control of the insect pests infesting stored food and other products, and as an essential part of his provision for the training of applied entomologists he built up during the years preceding the Second World War an extremely active Biological Field Station at Slough. The work carried out there laid a firm foundation for the control of stored products pests, and it was a fitting tribute to him that after the outbreak of war in 1939 the organization passed smoothly and efficiently into new control and became the Pest Infestation Laboratory of the Department of Scientific and Industrial Research.
After the War, undaunted by difficulties, Munro set himself the task of building up another field station, at Silwood Park, fully capable of carrying on the tradition established at Slough. With the heavy responsibilities of his duties as director of the Field Station added to those he bore as head of the Department of Zoology and Applied Entomology, and with the essential burden of maintaining an intimate connexion with industry, it was inevitable that Munro's personal researches should suffer; but it is gratifying that the stimulus and opportunity he gave to others, together with his wise and patient guidance and an outlook which passed beyond the walls of the laboratory, has resulted in a body of original work and endeavour of which he may be justly proud. Throughout the Commonwealth the number of Imperial College-trained field entomologists bears witness to Prof. Munro's success in guiding and promoting the training of his students. He has held the balance fairly between laboratory discipline and field studies, and his students have been able to acquit themselves well in widely differing fields of work. Prof. Munro was made C.B.E. in 1950.

\section{Dr. O. W. Richards}

Dr. O. W. Richards, who succeeds Prof. J. W. Munro, is well known as a distinguished entomologist. A graduate of Oxford, he became lecturer in entomology in the Imperial College in 1931, received his doctorate in 1934, and was appointed assistant professor in 1938. For many years he has been closely associated with the activities of the Royal Entomological Society, becoming a Fellow in 1924, secretary during 1937-40, and serving for three terms of office on its Council between 1931 and 1945 ; he was vice-president in 1935. Richards is perhaps best known for his interest and work on the biology 